\title{
The Aesthetic Generality between Chinese Architecture and Chinese Opera
}

\author{
Li Meng ${ }^{1, a}$ \\ ${ }^{1}$ School of Architecture, South China University of Technology, Guangzhou 510641, China \\ abambooleaf121@126.com
}

\begin{abstract}
Keywords: Aesthetic generality, spatiotemporal nature, decorative characteristics, sense of rhythm, educational feature, Chinese architecture, Chinese opera

Abstract. Chinese architecture and Chinese opera both enjoy a long history and reveal the Chinese cultural spirit. This study aims to investigate the generality between Chinese architecture and Chinese opera and therefore to enrich the architectural theory as well as to improve the architectural practice. Chinese architecture and Chinese opera share four main aesthetic principles, namely, spatiotemporal nature, decorative characteristics, sense of rhythm, and educational feature. Each of the four principles is discussed and explained through classical examples of Chinese architecture and Chinese opera.
\end{abstract}

\section{Introduction}

Chinese architecture and Chinese opera both are the comprehensive artistic forms. Architecture is an organic unity of spatial art, formative art, landscape, and luminal art; while Chinese opera is a synthetic art integrating the factors of art, music, dance, literature, martial arts and acrobatics. There are mainly four common aesthetic principles applicable to both Chinese architecture and Chinese opera, namely, spatiotemporal nature, decorative characteristics, sense of rhythm, and educational feature. We will discuss each as follows.

\section{The Spatiotemporal Nature}

Chinese memorial architecture and Chinese opera share the similar spatiotemporal nature. Architecture is a typical art which forms a certain spatial and temporal sequence. The issue of spatiotemporal nature can be elaborated from two levels: the physical level, which talks about here and now; and the psychological level, which is mainly about the space and time created by the aesthetic subjects. Psychologically spatio-temporal nature generates from the aesthetic activities, leading people's imagination into certain visional space and time, in which some major events happened. "We visited Yingxiu Epicenter Memorial Hall in Sichuan province on July 31st, 2016", expressing the physical time, namely "July 31st, 2016" and place "Memorial Hall". The architects imitated a cottage inside the hall, recalling the visitors' memory of the miserable moment when Wenchuan earthquake occured in May 12th, 2008 [1]. In such a virtual reality, people could suffer the pain of the disaster and experience the anticipation of the reconstruction. Thus, this psychological space-time is "there" and "then", namely "the cottage" and "May 12th, 2008".

Chinese opera has, both physically and psychologically, the same spatiotemporal features. Opera always needs to be performed in a physical time and space, which are called "theater schedule" and "theater location", respectively. For instance, during the Qing Dynasty, people used to gather around in Foshan Ancestral Temple to appreciate Chinese opera which were performed in order to celebrate some traditional festivals. In this case, "festival" and "opera stage" are the "theater schedule" and "theater location", respectively. For modern Chinese opera, the "theater location" is not totally fixed. The modern opera Dream.Red Boat is performed on a ship in the Pearl River. The temporary structures have been set up on the ship, thus the performing space could include all the halls, balconies and corridors. Mechanical devices have been arranged in the center of the vestibule, so that the stage is movable according to the script's requirements. Besides, there is also a removable model of flower 
boat on which performers could stand and sing. In this modern opera, no distinct boundary exists between the spectators and performers because the "boundary" is vague and changeable. As the story goes on, performers and audiences move in an orderly manner, constantly transform their positions. All these positions could be considered as "theater location".

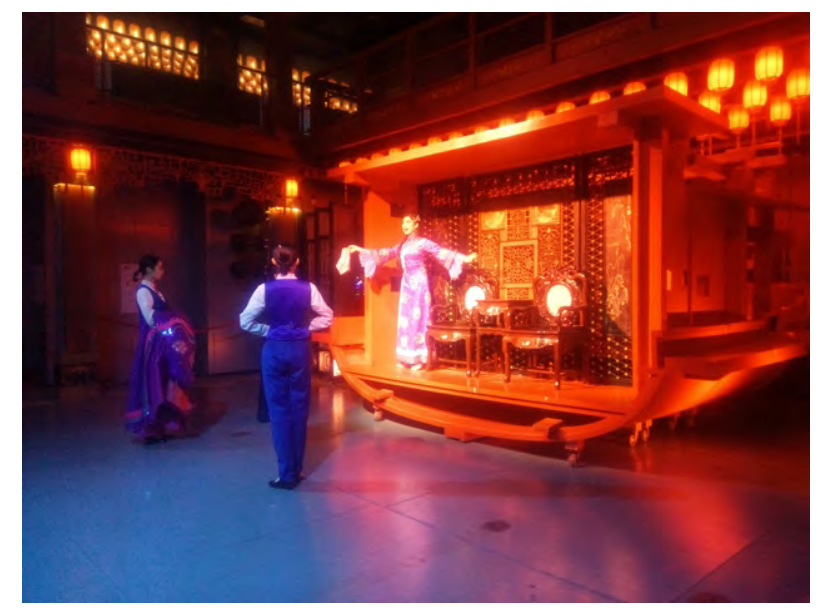

Fig.1 Model boat as the stage in Dream·red boat

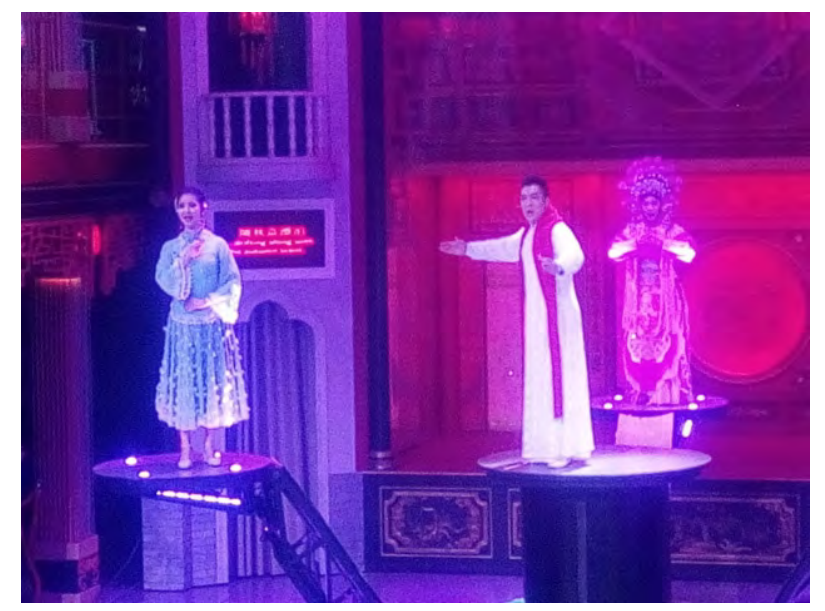

Fig.2 Movable stage in Dream·red boat

Chinese opera also has some virtual time and space, which can be called "stage time" and "stage space". They can break through the limitation of "theater schedule" and "theater location", representing events that occur anytime and anywhere. "What the opera pursues is not the physical reality of shape, weight, quality, speed, strength or frequency, but the psychological sense of feeling, mood, perception, imagination, emotion, and atmosphere created by the live performance. The psychological sense, in return, is added to the reality of the opera.'[2] During the performance, audiences are often unconsciously attracted to the virtual space and time, which convert frequently with the plots. In this situation, people become aesthetic subjects, temporarily forget about the real environment, produce emotional resonance, and attain the state of aesthetic transcendence. Mei Lanfang, a master of the traditional Chinese opera, once asked an old lady about her viewing experience towards the Sichuan opera Autumn River. "Brilliant! Just a little bit dizzy because of my seasickness. I was so absorbed as if I were sitting on the boat, that I felt dizzy unconsciously."[3]

In addition to sharing the physical - psychological duality in obvious spatiotemporal nature with Chinese opera, Chinese memorial architecture design sometimes attempts to introduce stories of Chinese opera as its decoration themes, which adds the cultural connotations to the buildings. Conversely, the architecture becomes the existing carrier to exhibit the content and spirit of Chinese opera. In some sense, the architecture develops a nice spatial relationship with the opera. People adopt opera stories as the themes of the decoration of the traditional ancestral halls in South China. The themes of decoration usually represent the figures in various techniques. Ridges, façades, beam frames, and screen doors are usually important components of the ornamentation. The operas, which tell stories taking place in different dynasties in ancient China, bring the visitors back to certain occasions and historical moments in the way of imagination. For example, the wood carving Guo Ziyi's Birthday Party represents the celebration scene in Tang Dynasty (618-907 A.D.), in Guo Ziyi's Fenyang Mansion. The brick engraving Liu Qing Tame the Unruly Horse comes from an opera story in royal palace which happened in Song Dynasty (960-1279 A.D.). As visitors walk through the ancestral hall, their psychological time and space change with the decorations of opera themes. By giving people sufficient aesthetic experience in this way, the spatiotemporal nature in Chinese opera has been closely connected with the traditional architecture. 


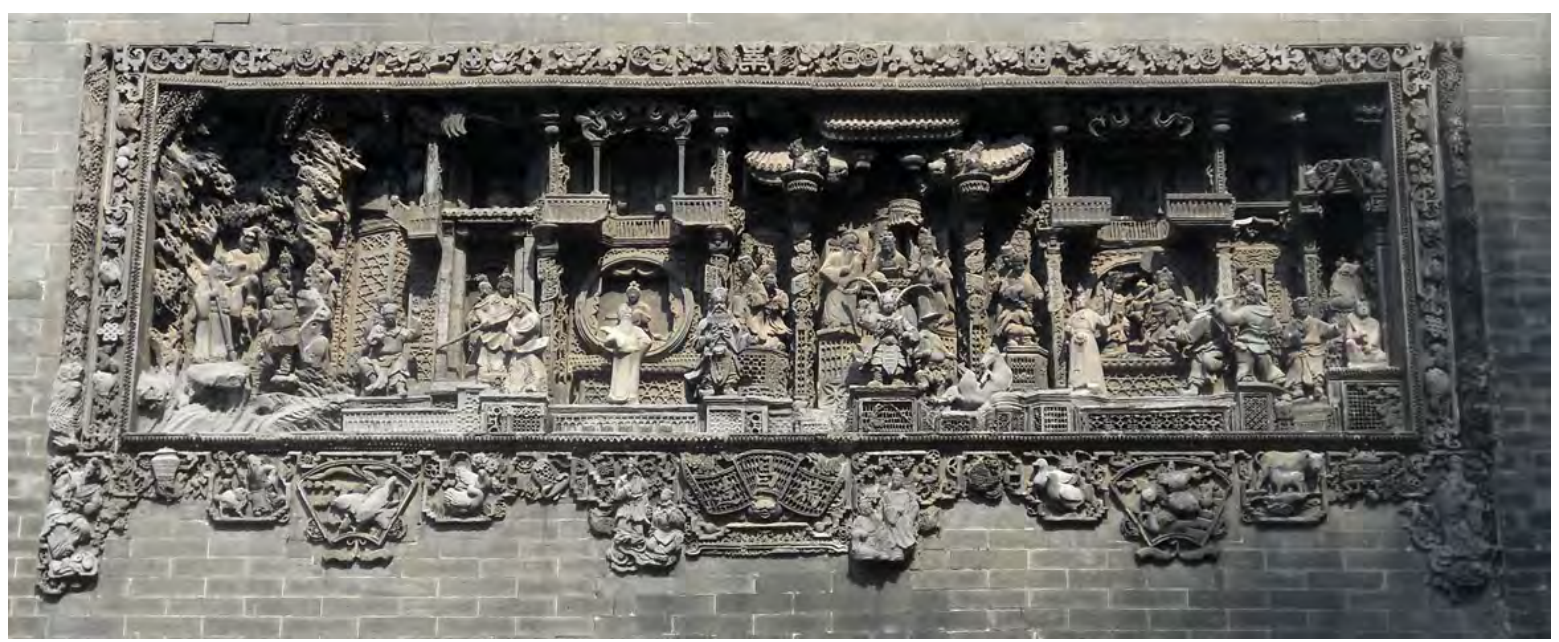

Fig.3 The brick carving Liu Qing Tame the Unruly Horse of Chen Clan Academy in Guangzhou

In this opera story, Liu Qing was a general in Song Dynasty. Several Tanguts come to the royal palace with an unruly horse, threatening the Emperor that if no Chinese tamed it, they would start a war against the Song Dynasty. Liu Qing successfully finished the task and saved the country.

\section{Decorative Characteristics}

Chinese architecture and Chinese opera are decorative. Certain ornament techniques are widely used in Chinese architecture such as wood engraving, brick carving, stone carving, ceramic sculpture, porcelain inlay, stucco statue and painting, etc. Comparatively, the decorative characteristics of Chinese opera represent in the facial makeup, costume, stagecraft, and so on.

Taking the Ancestral Temples in Chaozhou for example, they are extremely famous for their marvelous decorations. Chaozhou is located in the southeast of Guangdong province, not far away from the sea. Summer hurricanes did a lot of damage to the local constructions in the ancient time. Therefore, defensive measures are adopted to preserve the traditional buildings. For example, craftsmen often chose stone carving instead of wood carving to beautify temples' façades, not only because stone is more precious, but also because stone can protect the architecture from winds, moisture and corrosion. Ocean civilization shows a strong influence on Cong Xi Ancestral Hall, which is a major historical monument under state protection. Fish, crabs, seabirds, lobsters and a scene of fishing are carved and painted, in order to celebrate the richness of sea and express the joy of harvest [4]. As for the interior, craftsmen applied wood carvings to the beam frames, and coated the surface with gold lacquer, so that the ancestral hall would become more resplendent and magnificent. Lion is an auspicious and honorable animal, "lion" is thus the homophonic word of "teacher". In Jilue Huang Ancestral Hall, craftsmen engraved small figures of children and Taoists stand on the lions' mane, which means "Great masters make great men" (ming shi gao tu) and "Teachers carry the truth"(shi yi zai dao) in Chinese idioms.

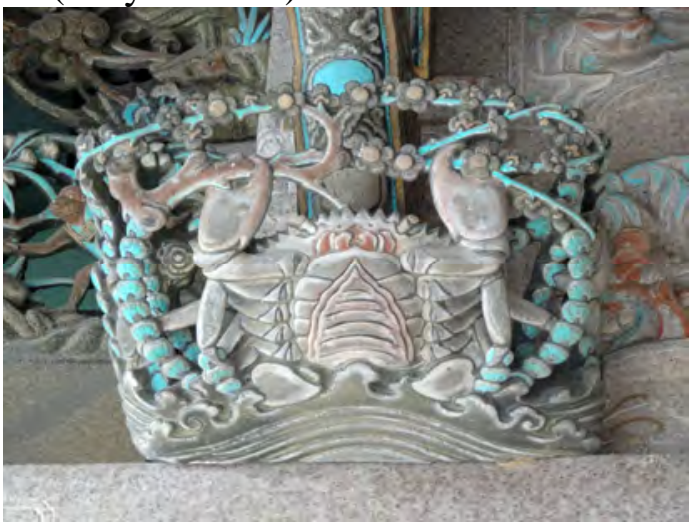

Fig.4 Stone engraving in Cong Xi Ancestral Hall

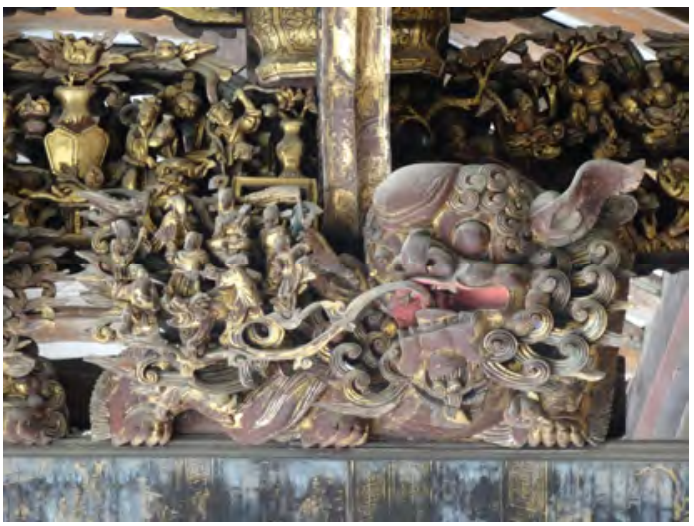

Fig.5 Wood carvings in Jilue Huang Ancestral Hall 
Modern Chinese architecture focuses more on the texture of the material than handicraft. Qian Xuesen Library in Shanghai Jiao Tong University is an outstanding architecture designed by He Jingtang and his team members. It is well-known that Qian Xuesen is an excellent scientist who dedicated his whole life to Rocketry and Space technology, making a great progress. The architects conceived the idea of "Rock split from inside", which highly affirmed Qian's contribution to China. GRC artificial stone was selected as the material of exterior wall, representing Qian Xuesen's portrait by a pixelated imaging approach. What's more, the portrait is visible when one appreciates it from a distance, and melts into the fabrics of the wall when one gets closer to the building [5].

Chinese opera shows the similar decorative features. Cantonese opera performers make up according to the roles' personality. "Black-and-white face" shows the attribute of integrity, frankness, and loyalty of the characters, therefore it is suitable for the roles such as Bao Zheng, Zhang Fei, and Li Kui. "Three tiles" is a kind of makeup which consists of black, white, and red colors [6]. The painting skills of "Three tiles" are so free and lively that it is appropriate for both the faithful and evil characters. "Five-color face" refers to the facial makeup with variety of colors such as red, yellow, green, black, and white. Some of the "Five-color face" would even use gold, blue, and purple, in order to manifest the characteristics of a king of the hill, a general, or a minister. An actor of Li Yuanba, a powerful general in Tang Dynasty, adopted "Five-color face" as his facial makeup. In the traditional Chinese opera, different colors and patterns express different decorative features and symbolic meanings. They suggest the roles' statuses, personalities, and even fates, so that the audience would recognize them immediately.

Decorative characteristics are also presented in the traditional Cantonese opera costumes. For example, the costume "Mang" is a kind of robe which is designed for the Emperor, Prime minister, marshal, or official, with various loong-patterns embroidered on it. Another kind of costume "Kao", specially planned for the military generals, is sewed with sheet copper and glass mirrors, in order to imitate a suit of armor. By contrast, "Zhe $\mathrm{Zi}$ " is appropriate for both the literati and warrior, and is decorated in different colors such as blue, red, yellow, white, black, and purple. "Kai Chang", a ceremonial dress, is for the role of warriors. Tiger and leopard patterns are embroidered on it instead of loong, as the rank of "Kai Chang" is much lower than "Mang"[7]. During the Ming Dynasty (1368-1644 A.D.), People used to define the military hierarchical grade (called the Nine-rank system) by linking the auspicious animal patterns to the officers' titles. For instance, kirin, lion, leopard, tiger, bear, and rhino represent the ranks from the highest to the lowest, respectively. In this way, in an opera, audience could judge the characters' identities by distinguish the animals sewed on their costumes at a glance.

\section{Sense of Rhythm}

Sense of rhythm is another important aesthetic generality between Chinese architecture and opera. Rhythm refers to the phenomenon of regular repetition and organized change in artistic expression. It is usually emotional and expressive.

Chinese architecture develops a sense of rhythm, which is obtained through the constant repetition and changes of some elements. Rhythm of architecture could be categorized into continuous rhythm, gradual rhythm, fluctuating rhythm and intertwining rhythm. For example, the facades of Hebei Dachang National Palace have many arch doors, and the repeated arch doors form a sense of rhythm by the continuous shapes. Inspired by the traditional Chinese Dougong, crowns and utensils, the "Oriental Crown" applies modern constructing technology and establishes a well-organized cantilevered space system, showing a gradual change in its appearance. The roof of Ningbo Fellowship Museum in Zhejiang Province adopts the ancient patterns, which combine certain artistic techniques to create an intertwining rhythm.

The sense of rhythm can be captured in Cantonese opera music, which can be divided into two categories: vocal music and instrumental music. Vocal music harmonizes with the nine tones of 
Cantonese, combining with "Bang Zi", "Er Huang", kunqu, as well as southern sounds and other local tunes[8]. "Bang Zi" originates from "Xipi", a northern tone that is high and fervid; while "Er Huang" inherits the euphemistic style of the southern music. The melody of "Bang Zi" and "Er Huang" comes out to be a graceful cadence, presenting the audience with beautiful musical rise and fall. Further more, during the 1920s-1930s, Cantonese opera performers absorbed the musical elements from other musical forms, like the western pop music, the aria in western opera, and the local mandarin pop music, thus finally created a unique Sino-west opera style. And instrumental music is composed of timbal and Orchestra. Timbal coordinates and adjusts to the rhythm of the opera, while orchestra plays a role of activating the atmosphere.

\section{Educational Feature}

Educational feature is distinct in Chinese architecture as well as in Chinese opera.Traditional Chinese architecture highlights the concept of patriarchal rites and music, which can be seen from its themes of decorations. The subject of plum, orchid, bamboo and chrysanthemum symbolizes loftiness, while that of pomegranates and grapes implies fertility and fortune. Modern Chinese architecture inherits the educational feature of traditional ones and emphasizes the spiritual expression. Museum of Liang Qichao's Former Residence, designed by the famous architect Mo Bozhi, displayed Liang Qichao's patriotism and his efforts to promote the Constitutional Reform and Modernization in 1898 through combining the Chinese and western architectural techniques and methods. XinZhu Garden in Macao places a pool and artificial hills in its atrium, with a huge character "gui" (means "coming back") on the surface of a rock, reflecting the Macanese's expectation to return to China.

Opera is one of the most important ways of entertainment in ancient China. Since the literacy rate was not very high at that time, most people acquired their historical knowledge by watching opera. Generally speaking, in Chinese opera stories, evil is always punished and good deeds are promoted, praising loyalty and courage of the characters. During Ming (1368-1644A.D.) and Qing Dynasties (1644-1911A.D.), operas began to show the spirit and courage of young men and women in pursuit of love and rebellion against the fetters of feudal ethics. From 1840 to 1949, China was in such a precarious situation that the opera took on the important task of disseminating revolutionary ideas and promoting the survival of the nation. Operas have been endowed with various spiritual connotations as time goes by. They cultivate people's aesthetic taste and improve the aesthetic standards.

Since the time of Confucius, education has always been essential for both the country and the families. "Beauty in kindness" is a favorable principle which keeps Chinese architecture, Chinese opera, and other artistic forms associated with each other.

\section{Conclusions}

Aesthetic generality is a basic law of art. Four common aesthetic characteristics between Chinese architecture and Chinese opera are discussed, namely, spatiotemporal nature, decorative characteristics, sense of rhythm, and educational feature. China enjoys a long history and has a vast territory, therefore, architecture and opera in different periods and regions show different characteristics. Moreover, Chinese architecture is a kind of comprehensive art, therefore the aesthetic generality does not exist only between architecture and opera, but also between architecture and other artistic forms, such as calligraphy and Chinese painting. Further exploration is in demand to deepen our understanding and broaden our knowledge related to this topic.

\section{Acknowledgements}

This work was financially supported by the General Program of the National Natural Science Foundation of China: Research on Realistic Design Theory and Development Process of Lingnan Architecture School (Project Number:51378212) and by Guangzhou Science and Technology Plan Project: The Demonstration and Renovation of the Existing Buildings in the Rural Area of 
Guangzhou Based on the Regional Characteristics and Green Building Technology (Project Number: 201804020017).

\section{References}

[1] Architectural Design and Research Institute of South China University of Technology: He JingTang Architectural Design. (South China University of Technology Press, Guangzhou 2010)

[2] Shen Daren: Opera Image Theory (Culture and Art Publishing House, Beijing 2014).

[3] Mei Lanfang: Mei Lanfang Anthology (China drama publishing house, Beijing 1981).

[4] Cai Haisong: Chaoshan Vernacular Architecture (Culture and Art Publishing House, Beijing 2010).

[5] Architectural Design and Research Institute of South China University of Technology: Culture/Expo Architecture (South China University of Technology Press, Guangzhou, 2012).

[6] Luan Guanhua: Role Symbols: Facial Makeup of Chinese Opera. (SDX Joint Publishing Company, Beijing 2005).

[7] Regional Council: Cantonese Opera Costumes. (Published by the Regional Council, Hong Kong, 1988).

[8] Luo Mingen, Luo Li : Cantonese Opera (Guangdong Education Press, Guangzhou 2010). 